\title{
Growth Mindset in Computational Thinking Teaching and Teacher Training
}

\author{
Michael Lodi \\ Dep. of Computer Science and Engineering (DISI) \\ University of Bologna, Italy \\ michael.lodi2@unibo.it
}

\begin{abstract}
Teacher training in computational thinking is becoming more and more important, as many countries are introducing it at all $\mathrm{K}-12$ school levels. Introductory programming courses are known to be difficult and some studies suggest they foster a fixed-mindset views of intelligence, reinforcing the idea that only some people have the so called "geek gene". This is particularly dangerous if thought by future school teachers. Interventions to stimulate "CS growth mindset" in students and their teachers are fundamental and worth CS education research.
\end{abstract}

\section{KEYWORDS}

Computational Thinking; Growth Mindset; Teacher Training

\section{ACM Reference format:}

Michael Lodi. 2017. Growth Mindset in Computational Thinking Teaching and Teacher Training. In Proceedings of ICER'17, August 18-20, 2017, Tacoma, WA, USA., , 3 pages.

DOI: http://dx.doi.org/10.1145/3105726.3105736

\section{PROGRAM CONTEXT}

I'm halfway through the first year of the three-year $\mathrm{PhD}$ program in Computer Science and Engineering at University of Bologna, Italy. I anticipate to pass qualifying exams within Summer 2017. I have to make my thesis proposal within January 2018 and work on it full time (except for the yearly 60 hours of teaching assistance) till November 2019. For my Master Thesis I worked on a literature review of Computational Thinking and on the cognitive difficulties of learning to program. In the first months of $\mathrm{PhD}$ I worked on teacher training: I analyzed [2] teachers' sentiment about Programma il Futuro project and their conceptions and misconceptions [3] about computational thinking. Moreover I'm analyzing data on the effects of a "Creative Computing" course on Primary Education Major students' growth mindset, with promising preliminary results.

\section{CONTEXT AND MOTIVATION}

In the last decade, computational thinking has been recognized as a fundamental skill for everyone, not just for computer scientists [12]. Many countries in the world are making efforts to include it in the school curriculum, at all K-12 levels.

In Italy, the recent school system reform explicitly states that it is mandatory to develop students' digital skills, with particular

ICER'17, August 18-20, 2017, Tacoma, WA, USA.

(C) 2017 Copyright held by the owner/author(s). This is the author's version of the work. It is posted here for your personal use. Not for redistribution. The definitive Version of Record was published in Proceedings of ICER'17, , http://dx.doi.org/http //dx.doi.org/10.1145/3105726.3105736. attention to the development of computational thinking. In perspective, computational thinking is going to be introduced in Italian teaching curriculum. These pushes to teach computational thinking, mainly through teaching programming ("coding"), give rise to the necessity of an urgent plan for teacher training, both for pre-service and in-service ones, and especially for Primary School teachers, that - in Italy - are mostly female and generally not trained to teach computer science fundamentals.

Learning to program may appear a too challenging task, achievable only from those with a so called "geek gene" [10]. Moreover, stereotypes lead to consider computer scientists as singularly focused, asocial, competitive, male figures [9].

Students and teachers have different personal ideas ("implicit theories") about their intellectual abilities. Some believe their intelligence is a fixed trait (like eye color or height when adult), and they can't do much to change it: they have an entity theory of intelligence, otherwise stated a fixed mindset. Some other believe that intelligence can be developed with study and effort (like muscles being trained): they have an incremental theory of intelligence, also called a growth mindset. Mindsets theory is a fundamental result of Carol Dweck's research [5]. In many studies she showed, among other things, that students' mindset can predict their achievement - especially in Math and Science [6] and their ability to cope with challenges. Moreover, female students with growth mindset showed less susceptibility to negative effects of stereotypes about women and Math [8].

\section{BACKGROUND \& RELATED WORK}

As known, the term computational thinking (CT) was brought to the attention of our community by Jeannette Wing [12], that later defined it as "the thought processes involved in formulating problems and their solutions so that the solutions are represented in a form that can be effectively carried out by an information-processing agent" [13]. How to effectively teach computational thinking is highly debated, but the most popular methodology at the moment is to teach programming (with languages and environments suitable for different learners).

Dweck's studies on growth mindset are based on three decades of research. Students with growth mindset show learning-oriented goals (not afraid to ask and make errors, in order to learn) and a mastery-oriented responses (greater effort and new strategies) to challenges and setbacks, while students with fixed mindset show performance goals ("appear intelligent", so avoiding difficult tasks) and and helpless response to challenges (e.g. giving up or blaming teachers for their failure). Growth mindset can be positively conveyed by explicitly teaching students about mindsets, brain plasticity and the idea that intelligence can be trained; by portraying 
challenges and mistakes as highly valued; by praising process, and give constructive feedback rather than praising the person or being judgmental. Moreover, specific suggestions to stimulate a "Math growth mindset" includes giving rich open tasks, that require effort, reasoning, creativity [1]. Teachers' conceptions are crucial: growth minded people are more supportive with students, give encouragement and suggest positive strategies to deal with problems; by contrast, fixed minded people give students simple comfort and fixed messages and tend to help boys significantly more than girls [6].

Only a few studies have been conducted to assess and/or alter students' mindset before and after a programming course. Simon et al. [11] tried a small intervention in CS1 classes to change mindset of students form CS Majors and Minors, but they obtained mixed results. Cutts et al. [4] performed three structured interventions into an introductory programming course, gaining significant improvement in growth mindset level of students and also a positive correlation with their test scores. By contrast, Flanigan et al. [7] analyzed (without intervention) changes in students of CS courses across the semester, finding a significant increase in fixed mindset and a significant decrease in growth mindset.

\section{STATEMENT OF THESIS/PROBLEM}

A general research question of my work is: What are the relationships between Growth Mindset, Computational Thinking Teaching and Computational Thinking Teacher Training? Specifically some sub-problems to address are:

- What are the effects of computational thinking introductory courses on teachers and students mindsets?

- What are the effects of teachers mindset (in particular regarding CS) on students learning of computational thinking?

- What specific aspects of computational thinking / computer science / programming induce a more fixed mindset? And what aspects induce a growth mindset?

- Can computational thinking specifically designed activities help to induce a "CS growth mindset" in teachers and in their students?

\section{RESEARCH GOALS \& METHODS}

Pre and post questionnaires that measure growth mindset of participants (K-12 students or Education Majors students or in-service teachers) before and after an intervention (a computational thinking course) using well validated growth mindset scales will be administered; control groups (e.g. other Education Major students that don't follow the course with intervention) are foreseen.

Qualitative research approaches, like grounded theory, with interviews and open-ended questions deep analysis will be used to determine which specific aspects of computational thinking can increase (or decrease) growth mindset in participants.

Classroom experimentation (both in K-12 schools and in teacher training courses) to validate proposed materials will be conducted and mindset changes measured.

\section{DISSERTATION STATUS}

The literature review on CT and the work on teachers' conceptions can become part of the introductory chapters of my thesis, while the data I'm collecting on growth mindset will be part of the experimental chapters: a preliminary analysis gives promising results in leveraging teachers mindset. I plan to find out what aspects of the course are useful to induce a growth mindset, and then to propose and test a series of ad-hoc materials to be used in teacher training courses and/or in schools.

\section{EXPECTED CONTRIBUTIONS}

Growth mindset has been recognized as a crucial aspect to foster students' success and to reduce gender and social gap. General interventions to increase growth mindset have been proposed. Moreover, people can have fixed mindset related to specific disciplines like Math or Computer Science that are typically connected with fixed views of "being or not being predisposed", so specific interventions can help to modify these ideas. Finally, teachers' mindsets have a profound impact on students' mindset development and success in the discipline, so specific teacher training interventions must be designed and tested.

\section{EXPECTED LEARNING FROM DC}

I think attending ICER Doctoral Consortium 2017 is a great opportunity to grow as a researcher.

My background is in (theoretical) computer science, and only in the last part of my Master Degree I started to get used to social and educational research methods: I really look forward to learning more about education research from participants with different backgrounds.

Moreover, in Italy CS Education is not (yet) a trending topic for academic career in CS, so I hope to broaden my views on which specific topics are worth to be investigated in this field.

\section{REFERENCES}

[1] Jo Boaler. 2013. Ability and mathematics: the mindset revolution that is reshaping education. In Forum, Vol. 55. Symposium Journals, 143-152.

[2] Isabella Corradini, Michael Lodi, and Enrico Nardelli. 2017. Computational Thinking in Italian Schools: Quantitative Data and Teachers' Sentiment Analysis after Two Years of "Programma il Futuro" Project (ITiCSE '17). ACM, New York, NY, USA.

[3] Isabella Corradini, Michael Lodi, and Enrico Nardelli. 2017. Conceptions and Misconceptions about Computational Thinking among Italian Primary School Teachers (ICER '17). ACM, New York, NY, USA.

[4] Quintin Cutts, Emily Cutts, Stephen Draper, Patrick O'Donnell, and Peter Saffrey. 2010. Manipulating mindset to positively influence introductory programming performance. SIGCSE '10 (2010). https://doi.org/10.1145/1734263.1734409

[5] Carol S Dweck. 2000. Self-theories: Their role in motivation, personality, and development. Psychology Press.

[6] Carol S Dweck. 2008. Mindsets and Math/Science Achievement. The Opportunity Equation (2008).

[7] Abraham E. Flanigan, Markeya S. Peteranetz, Duane F. Shell, and Leen-Kiat Soh. 2015. Exploring Changes in Computer Science Students' Implicit Theories of Intelligence Across the Semester. ICER '15 (2015). https://doi.org/10.1145/ 2787622.2787722

[8] Catherine Good, Aneeta Rattan, and Carol S. Dweck. 2012. Why do women opt out? Sense of belonging and women's representation in mathematics. Fournal of Personality and Social Psychology 102, 4 (2012), 700-717. https://doi.org/10.1037/ a0026659

[9] Colleen M. Lewis, Ruth E. Anderson, and Ken Yasuhara. 2016. "I Don't Code All Day”. ICER '16 (2016). https://doi.org/10.1145/2960310.2960332

[10] Elizabeth Patitsas, Jesse Berlin, Michelle Craig, and Steve Easterbrook. 2016. Evidence That Computer Science Grades Are Not Bimodal (ICER '16). ACM, NY, USA, 9. https://doi.org/10.1145/2960310.2960312 
[11] Beth Simon, Brian Hanks, Laurie Murphy, Sue Fitzgerald, Renée McCauley, Lynda Thomas, and Carol Zander. 2008. Saying isn't necessarily believing. ICER '08 (2008). https://doi.org/10.1145/1404520.1404537

[12] Jeannette M. Wing. 2006. Computational Thinking. Commun. ACM 49, 3 (March 2006), 33-35. https://doi.org/10.1145/1118178.1118215

[13] Jeannette M. Wing. 2010. Computational Thinking: What and Why? Link Magazine (2010). 